\title{
Systolic time intervals in valvular aortic stenosis and idiopathic hypertrophic subaortic stenosis
}

\author{
Mohsen Ibrahim, ${ }^{1}$ Michele Silie, Jean-Pierre Delahaye, and Roger Froment \\ From Hôpital Cardiovasculaire et Pneumologique, Lyon, France
}

Corrected systolic time intervals of the left ventricle: the interval between the onset of the $Q$ wave and the first heart sound $(Q-M I)$, isovolumic contraction time $(I V C T)$, and left ventricular ejection time (LVET) have been measured by noninvasive techniques in 26 patients with valvular aortic stenosis and in 25 patients with idiopathic hypertrophic subaortic stenosis. The results were compared with the peak systolic pressure gradient across the aortic valve or the subaortic stenosis. It was shown that the Q-MI interval was pathologically long in patients with idiopathic hypertrophic subaortic stenosis. Isovolumic contraction time was derived by two different measurements (IVCT I and IVCT 2) and in both groups of patients it was shortened. A significant inverse relation was established between the gradient and the isovolumic contraction time only in patients with valvular aortic stenosis. When the LVET/IVCT I ratio was compared with the gradient, a linear correlation was demonstrated $(r=0.84, P<0.001)$ in patients with valvular aortic stenosis. In patients with idiopathic hypertrophic subaortic stenosis no single parameter was found to be of value in assessing the degree of intraventricular pressure gradient.

In recent years noninvasive techniques have gained wide acceptance as effective procedures for the study and evaluation of left ventricular function (Weissler, Harris, and Schoenfeld, 1969). Determination of the systolic time intervals has been performed in different diseases of the left ventricle (Jezek, 1963; Margolis, 1964; Weissler, Harris, and Schoenfeld, 1968). Jezek (1963) found that in patients with aortic stenosis there was pathological shortening of the isovolumic contraction time (IVCT) and prolongation of left ventricular ejection time (LVET). Prolonged LVET has been a known feature of valvular aortic stenosis for a long time (Katz and Feil, I926) and recently recognized in patients with idiopathic hypertrophic subaortic stenosis (Wigle, 1963). Apart from LVET few clinical studies of other systolic time intervals were made and a correlation with systolic pressure gradient has not been adequately investigated.

The aim of this report is (I) to measure these intervals in two groups of patients, one presenting with valvular aortic stenosis and the other with

Received 3I July 1972.

${ }^{1}$ Study carried out during the author's residency in the Department of Clinical Cardiology, Hôpital Cardiovasculaire et Pneumologique, Service du Pr. Froment. Present address: Research Division, The Cleveland Clinic Foundation, Cleveland, Ohio, U.S.A. idiopathic hypertrophic subaortic stenosis, and to compare these measurements with the results obtained in normal subjects, and (2) to determine whether the degree of aortic obstruction can be assessed from the externally measured systolic time intervals.

\section{Subjects and method}

Studies were performed on two groups of patients. The first comprised 26 patients where pure or dominant aortic valvular stenosis was present. Patients with more than trivial regurgitation were excluded from the study. The second group comprised 25 patients with idiopathic hypertrophic subaortic stenosis. In all the $5 \mathrm{I}$ patients the clinical diagnosis was confirmed by haemodynamic and angiographic studies. The peak systolic gradient across the aortic valve was measured in all 26 patients with aortic stenosis, by left heart catheterization in 25 , and at operation in a single patient. The pressure gradient ranged between 30 and $150 \mathrm{mmHg}$ with a mean of $76.7 \mathrm{mmHg}$. The intraventricular pressure gradient in all 25 patients with idiopathic hypertrophic subaortic stenosis was measured by left heart catheterization. The basal systolic gradient in this group ranged between 8 and IIO $\mathrm{mmHg}$, with a mean of $57.4 \mathrm{mmHg}$. The average age of patients with valvular aortic stenosis was 46 years, whereas the patients with idiopathic hypertrophic subaortic stenosis averaged 34.7 years. All patients studied were in sinus rhythm and had no bundle-branch block. None of them had clinical or radiological evidence of heart failure. 
The duration of the phases of left ventricular systole was measured from simultaneous recordings of the electrocardiogram, phonocardiogram, apex cardiogram, and indirect carotid arterial pulse using a multichannel Hellige photographic recorder and microphone. Recordings were obtained at a paper speed of 50 and $100 \mathrm{~mm}$ a second. The measurements made are shown diagrammatically in Fig. I. The onset of the mitral closure sound (MI) was measured only if the initial high frequency vibrations of this sound were clearly defined. The Q-MI interval was measured from recordings obtained over the mitral and tricuspid areas using low cutoff frequencies of 50 and $100 \mathrm{cps}$.

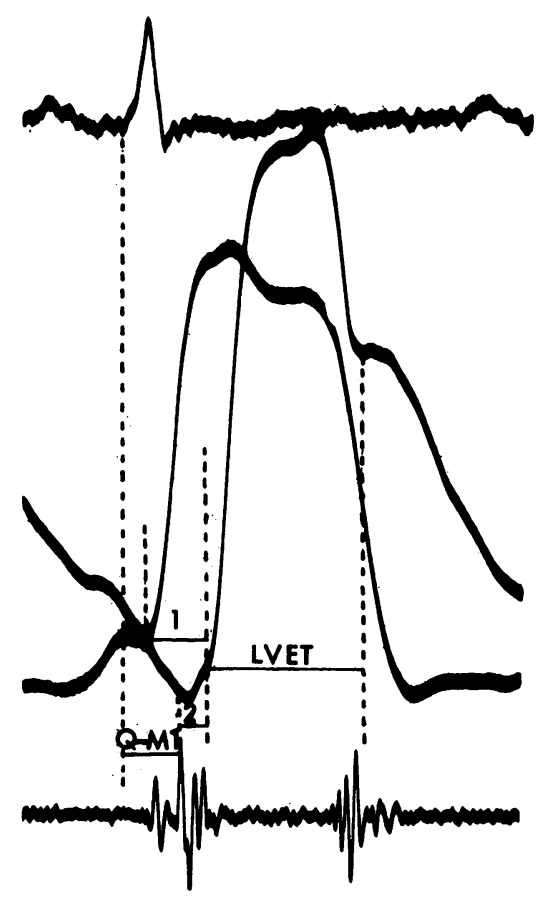

FIG. I Systolic time intervals defined by simultaneous recording of electrocardiogram, phonocardiogram, carotid pulse, and apex cardiogram. $I=I V C T I$; $2=I V C T 2$.

\section{Definitions of intervals (Fig. I)}

Q-MI The interval from the beginning of depolarization ( $Q$ wave in lead II in the standard electrocardiogram) to the initial high frequency vibrations of the first sound.

Isovolumic contraction time (IVCT) This was derived by two different measurements:

IVCT I From the beginning of apex cardiogram upstroke to that of the carotid upstroke.
IVCT 2 From the onset of the first rapid vibrations of the first heart sound to the beginning of the carotid upstroke.

Left ventricular ejection time (LVET) This is measured from the beginning of the upstroke to the trough of the incisure of the carotid arterial pulse tracing.

In addition to the above measurements the following two ratios were also calculated: LVET/IVCT I and LVET/IVCT 2.

All measurements were calculated from the mean of measurements made on 5 consecutive beats occurring mid to late expiration, each read to the nearest $5 \mathrm{msec}$. All the values were corrected for heart rate using the Bazett (1920) formula, dividing the absolute value by the square root of the preceding cycle length ( $R R$ interval). The findings provided by these means were correlated with the peak systolic pressure gradient which was used as an index of severity.

Statistical analysis was performed using the usual parametric statistical methods (regression and correlation coefficients).

\section{Results}

The results of this study are shown in Tables I and 2.

\section{Valvular aortic stenosis}

In this group we were not able to define the initial high frequency vibrations of the first heart sound in 7 patients; accordingly measurements of the Q-MI and IVCT 2 intervals were not made in these patients. The Q-MI interval ranged, in the group of patients in which it was measured, between 40 and $89 \mathrm{msec}$, with a mean of $66.3 \pm 14.7 \mathrm{msec}$. Fourteen out of 19 patients had a Q-MI interval more than $60 \mathrm{msec}$. The IVCT I ranged between 55 and $122 \mathrm{msec}$, with a mean of $85.5 \pm 20 \mathrm{msec}$. On the other hand, IVCT 2 ranged between 33 and $93 \mathrm{msec}$, with a mean of $56 \cdot 8 \pm 18 \mathrm{msec}$. Thirteen out of I9 patients had an IVCT 2 less than $60 \mathrm{msec}$; the LVET was between $28 \mathrm{I}$ and $420 \mathrm{msec}$, the mean was $359 \cdot 3 \pm 27 \cdot 1 \mathrm{msec}$. Out of 26 patients studied, 22 had an LVET more than $340 \mathrm{msec}$, the LVET/ IVCT I ratio ranging between 2.3 and 6.4 with a mean of 4.4 , while the LVET/IVCT 2 ratio was between 3.5 and 12.7 with a mean of 6.9. The majority of patients had an LVET/IVCT I ratio more than 4 .

When these measurements were compared with the peak systolic pressure gradient across the aortic valve, a significant correlation was established between the gradient and some of these parameters. Fig. 2 illustrates the significant linear correlation between LVET/IVCT I ratio and the peak systolic pressure gradient in patients with valvular aortic stenosis (correlation coefficient $=0.84$ ); the patients 
278 Ibrahim, Silie, Delahaye, and Froment

TABLE I Systolic time intervals (msec) in patients with valvular aortic stenosis

\begin{tabular}{|c|c|c|c|c|c|c|c|c|c|}
\hline Case & Age & Sex & $\begin{array}{l}\text { Pressure } \\
\text { gradient } \\
(\mathrm{mm} H \mathrm{~g})\end{array}$ & $Q-M I$ & $I V C T_{I}$ & $I V C T 2$ & $L V E T$ & $\frac{L V E T /}{I V C T I}$ & $\frac{L V E T /}{I V C T 2}$ \\
\hline $\mathbf{I}$ & 47 & F & 80 & 53 & 74 & 53 & 320 & $4 \cdot 3$ & 6 \\
\hline 2 & 44 & $\mathbf{M}$ & 60 & $8 \mathrm{I}$ & 106 & 81 & 360 & $3 \cdot 4$ & $4 \cdot 6$ \\
\hline 3 & I7 & $\mathbf{M}$ & I10 & 65 & 76 & 43 & 347 & $4 \cdot 6$ & 8 \\
\hline 4 & 45 & M & 120 & 88 & 77 & 33 & 420 & $5 \cdot 4$ & $12 \cdot 7$ \\
\hline 5 & 65 & $\mathbf{M}$ & 80 & 62 & 98 & 62 & 394 & $4 \cdot I$ & $6 \cdot 6$ \\
\hline 6 & 39 & $\mathbf{M}$ & 50 & 48 & 108 & 84 & 359 & $3 \cdot 3$ & $4 \cdot 3$ \\
\hline 7 & 47 & $\mathbf{F}$ & 30 & 61 & 122 & 92 & 281 & $2 \cdot 3$ & 3.5 \\
\hline 8 & 59 & $M$ & 130 & 63 & 63 & 42 & 358 & $5 \cdot 7$ & $8 \cdot 5$ \\
\hline 9 & 49 & $\mathbf{F}$ & 60 & 47 & 116 & 93 & 360 & $3 \cdot I$ & 3.9 \\
\hline 10 & 49 & $\mathbf{M}$ & 50 & 89 & II4 & 64 & 366 & $3 \cdot 1$ & $5 \cdot 6$ \\
\hline II & 48 & F & 150 & 46 & 57 & 46 & 367 & 6.4 & 8 \\
\hline 12 & 62 & $\mathbf{M}$ & 65 & 70 & 93 & 47 & 372 & 4.0 & 8 \\
\hline 13 & 63 & M & 100 & 68 & 79 & 45 & 408 & $5 \cdot 1$ & 9 \\
\hline 14 & 40 & $\mathbf{M}$ & 96 & 76 & 65 & 43 & 369 & $4 \cdot 9$ & 8.5 \\
\hline 15 & 47 & $\mathbf{M}$ & 60 & 72 & 92 & 51 & 369 & $4 \cdot 0$ & $7 \cdot 2$ \\
\hline 16 & 53 & $\mathrm{~F}$ & 100 & 67 & 67 & 56 & 369 & 5.5 & 6.6 \\
\hline 17 & 66 & F & II4 & 80 & 55 & 40 & 350 & $6 \cdot 4$ & $8 \cdot 7$ \\
\hline 18 & 60 & M & 66 & 40 & 65 & 55 & 320 & 4.9 & 5.8 \\
\hline 19 & 14 & $\mathbf{M}$ & 48 & 84 & 78 & 50 & 358 & $4 \cdot 6$ & $7 \cdot 1$ \\
\hline 20 & 56 & $\mathbf{M}$ & 3I & & 100 & & 350 & 3.5 & \\
\hline 21 & 21 & $\mathbf{M}$ & 90 & & 65 & & 367 & $5 \cdot 7$ & \\
\hline 22 & 34 & $\mathbf{M}$ & 86 & & 78 & & 369 & 4.7 & \\
\hline 23 & 48 & $\mathbf{M}$ & 50 & & II6 & & 358 & $3 \cdot 1$ & \\
\hline 24 & 9 & $\mathbf{M}$ & 44 & & 78 & & 347 & $4 \cdot 5$ & \\
\hline 25 & $6 I$ & $\mathbf{M}$ & 34 & & IOI & & 335 & $3 \cdot 3$ & \\
\hline 26 & 54 & $\mathbf{F}$ & 107 & & $8 I$ & & 370 & $4 \cdot 6$ & \\
\hline
\end{tabular}

TABLE 2 Systolic time intervals in patients with idiopathic hypertrophic subaortic stenosis

\begin{tabular}{|c|c|c|c|c|c|c|c|c|c|}
\hline Case & Age & Sex & $\begin{array}{l}\text { Pressure } \\
\text { gradient } \\
(\mathrm{mmHg})\end{array}$ & $Q-M I$ & $I V C T I$ & $I V C T 2$ & LVET & $\frac{L V E T /}{I V C T I}$ & $\frac{L V E T /}{I V C T 2}$ \\
\hline I & 43 & M & IO & 56 & 75 & 42 & 368 & 4.9 & $8 \cdot 7$ \\
\hline 2 & 26 & $\mathbf{M}$ & 40 & 89 & 67 & 45 & 436 & $6 \cdot 5$ & $9 \cdot 7$ \\
\hline 3 & 21 & F & 100 & 67 & IOI & 79 & 362 & $3 \cdot 6$ & $4 \cdot 6$ \\
\hline 4 & 44 & M & 108 & 90 & 84 & 54 & 388 & $4 \cdot 6$ & $7 \cdot 2$ \\
\hline 5 & 23 & M & 8 & 70 & 80 & 50 & 300 & $3 \cdot 8$ & 6.0 \\
\hline 6 & 45 & $\mathbf{M}$ & 50 & 76 & $8 I$ & 47 & 343 & $4 \cdot 2$ & $7 \cdot 3$ \\
\hline 7 & 50 & $\mathbf{M}$ & 36 & 83 & 72 & 51 & 312 & $4 \cdot 3$ & $6 \cdot 1$ \\
\hline 8 & 26 & M & 60 & 106 & 95 & 109 & 362 & 3.4 & $3 \cdot 3$ \\
\hline 9 & 16 & $\mathbf{M}$ & 40 & 76 & 98 & 66 & 286 & $2 \cdot 9$ & $4 \cdot 3$ \\
\hline 10 & 19 & $\mathrm{M}$ & 28 & 73 & 94 & 63 & 326 & $3 \cdot 5$ & $5 \cdot 2$ \\
\hline II & 52 & $M$ & 88 & 68 & 105 & 79 & 337 & $3 \cdot 2$ & $4 \cdot 3$ \\
\hline 12 & 40 & $\mathbf{M}$ & 32 & 95 & 76 & 57 & 295 & 3.9 & $5 \cdot 2$ \\
\hline 13 & 25 & $\mathbf{M}$ & 20 & 85 & 97 & 60 & 329 & $3 \cdot 4$ & $5 \cdot 5$ \\
\hline 14 & 54 & $\mathbf{M}$ & 12 & 82 & 82 & 71 & 348 & $4 \cdot 2$ & 4.9 \\
\hline 15 & 30 & $\mathrm{~F}$ & 70 & 97 & 78 & 59 & 339 & $4 \cdot 3$ & $5 \cdot 8$ \\
\hline 16 & 4I & $\mathbf{M}$ & 48 & 66 & 76 & 38 & 371 & 4.9 & $9 \cdot 8$ \\
\hline 17 & 39 & $\mathbf{M}$ & 72 & 75 & 103 & 62 & 381 & $3 \cdot 7$ & $6 \cdot 2$ \\
\hline 18 & II & $\mathbf{M}$ & 104 & 68 & 79 & 42 & 316 & 4.0 & $7 \cdot 5$ \\
\hline 19 & 36 & $\mathbf{M}$ & 50 & 89 & 71 & 29 & 406 & $5 \cdot 7$ & 140 \\
\hline 20 & 55 & F & IIo & 106 & 117 & 69 & 350 & $3 \cdot 0$ & $5 \cdot 1$ \\
\hline 21 & 28 & $\mathbf{M}$ & 100 & 67 & 98 & 39 & 359 & 3.0 & $9 \cdot 2$ \\
\hline 22 & 30 & $\mathbf{F}$ & 70 & 73 & 72 & 67 & 340 & $4 \cdot 7$ & $5 \cdot 1$ \\
\hline 23 & 53 & $\mathbf{F}$ & 40 & 43 & 86 & 65 & 358 & 4.2 & 5.5 \\
\hline 24 & 40 & $\mathbf{M}$ & 80 & 90 & 60 & 30 & 370 & $6 \cdot 2$ & $12 \cdot 3$ \\
\hline 25 & 21 & $\mathbf{M}$ & 60 & 60 & 80 & 60 & 350 & 4.4 & $5 \cdot 8$ \\
\hline
\end{tabular}




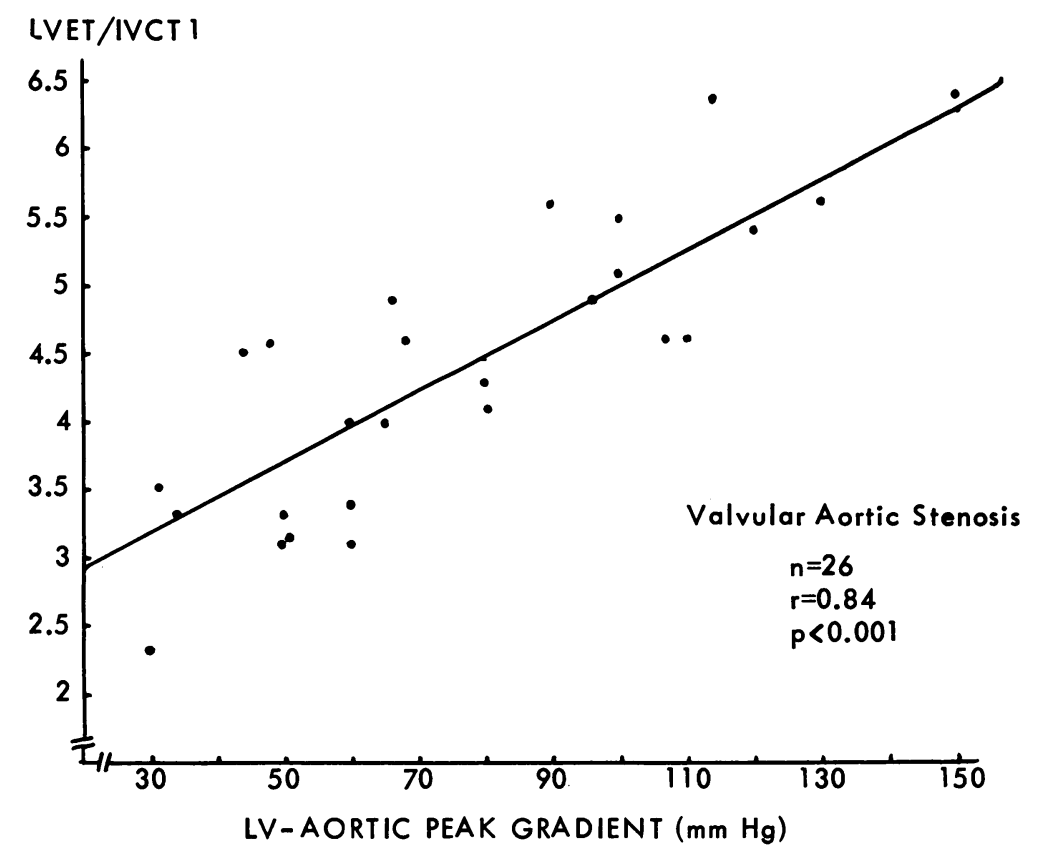

FIG. 2 Correlation between the LVET/IVCT I ratio and the peak systolic pressure gradient in 26 patients with valvular aortic stenosis.

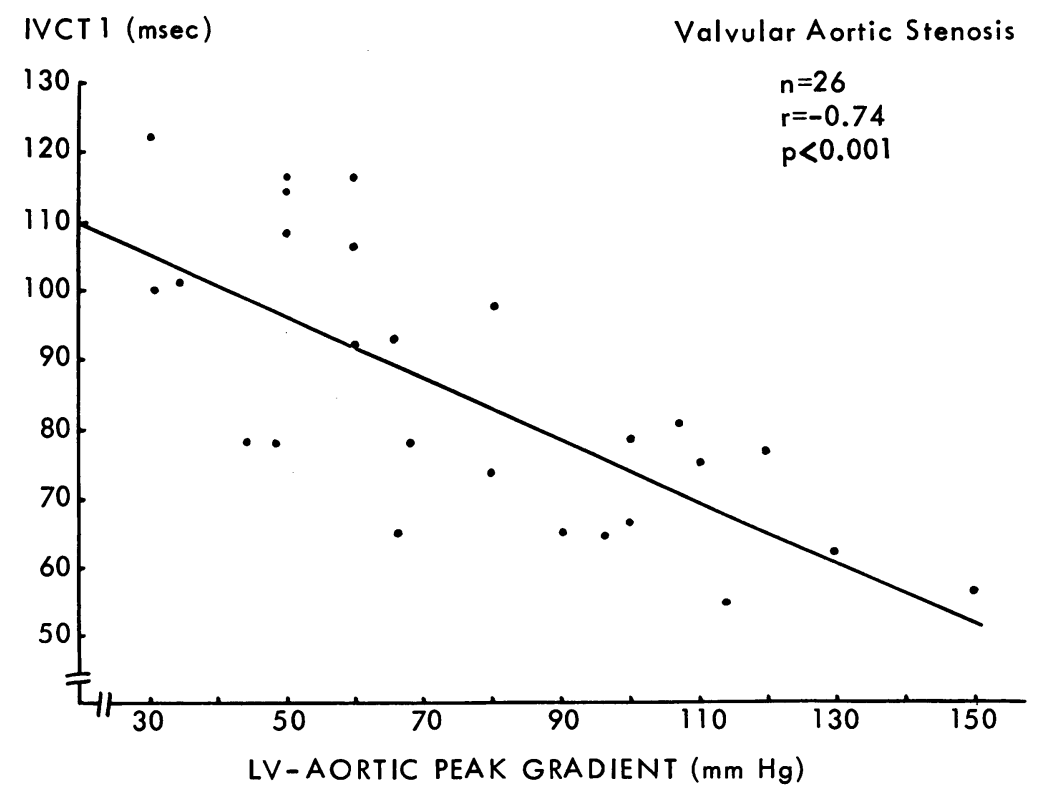

FIG. 3 Relation between the IVCT I interval and the peak systolic pressure gradient in patients with valvular stenosis. 


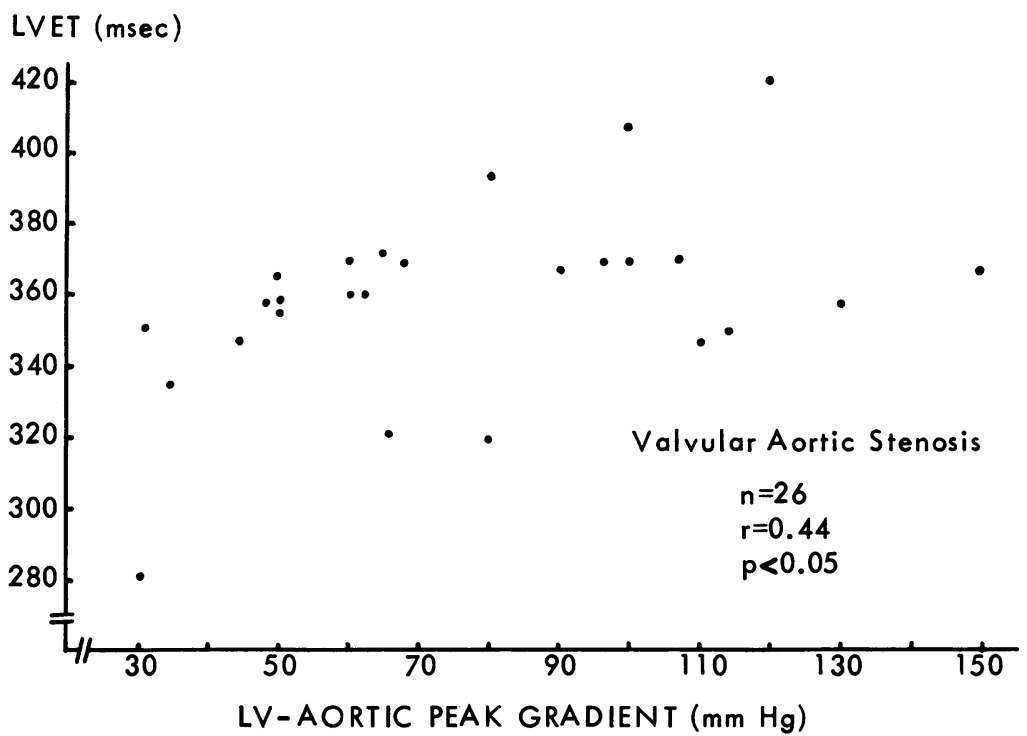

FIG 4 Diagram relating the LVET and the peak systolic pressure gradient in 26 patients with valvular aortic stenosis.

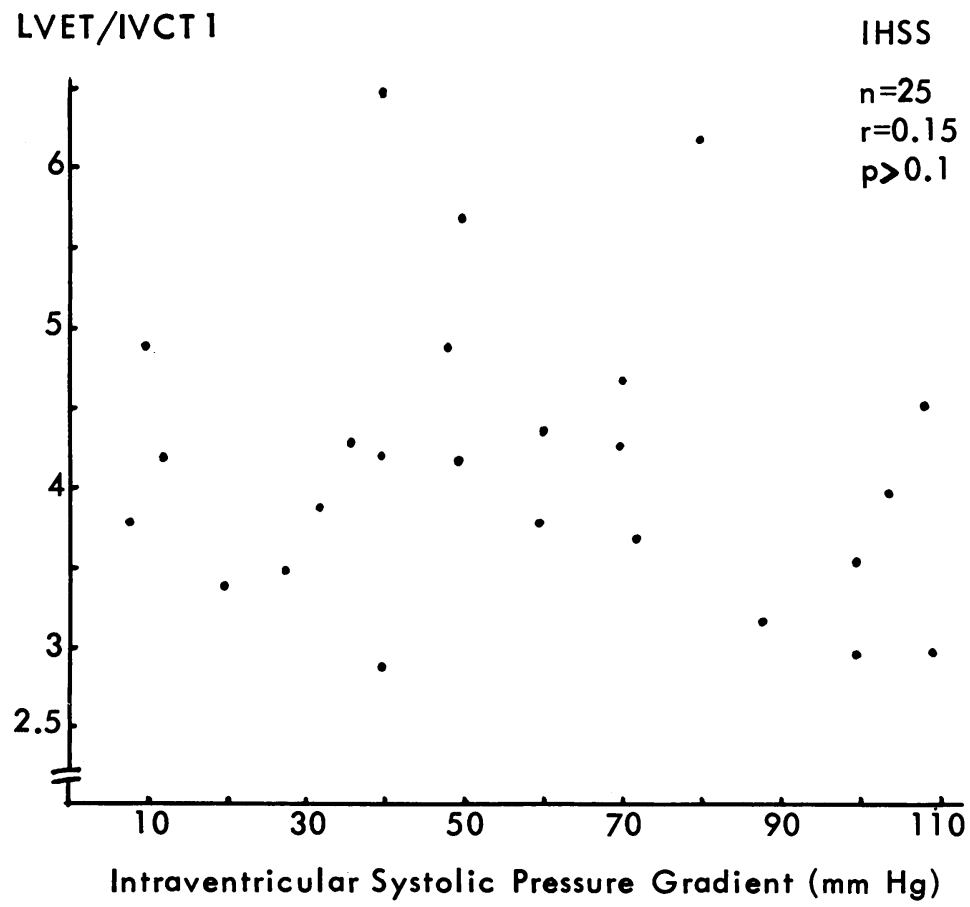

FIG. 5 Correlation between the LVET/IVCT I ratio and the intraventricular pressure gradient in 25 patients with idiopathic hypertrophic subaortic stenosis. 
with the lowest gradient had a lower LVET/IVCT $I$ ratio and patients with the most severe obstruction had a higher ratio. A significant correlation existed also between the LVET/IVCT 2 ratio and the pressure gradient $(r=0.72, P<0.01)$. Fig. 3 illustrates the relation between IVCT $I$ and peak systolic gradient: a significant inverse relation existed, patients with the lowest gradient having a higher IVCT I or IVCT 2, and patients with the most severe obstruction having the lowest IVCT. When LVET is compared with the gradient a fair correlation exists $(r=0.44)$; however, this relation is not linear (Fig. 4). There is no correlation between the gradient and Q-Mr interval.

\section{Idiopathic hypertrophic subaortic stenosis}

The Q-MI interval in this group was longer than in the first one; it ranged between 43 and $106 \mathrm{msec}$, with a mean of $78.4 \pm 14.8 \mathrm{msec}$. The majority of patients were found to have a Q-Mr more than 70 msec. Measurements of IVCT $\mathrm{r}$ and IVCT 2 were

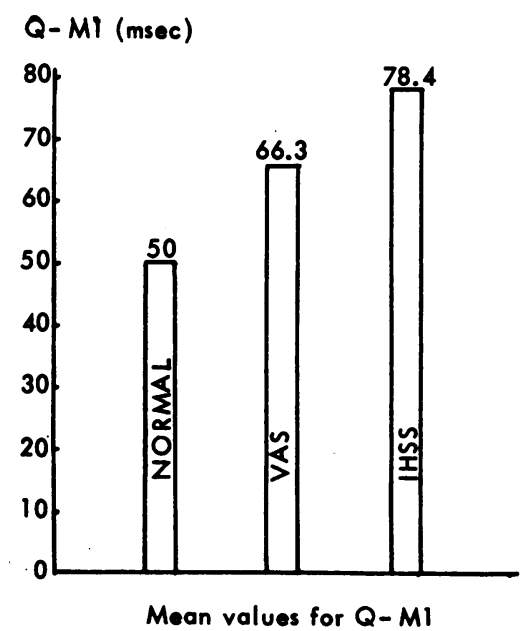

FIG. 6 Mean values of $Q-M I$ interval among patients with valvular aortic stenosis, idiopathic hypertrophic subaortic stenosis, and the normal subjects. The measurements of normal subjects in this study are based upon the study of Spodick and Kumar (1970).

very similar to those in patients with valvular aortic stenosis: the IVCT I was between 67 and $117 \mathrm{msec}$, with a mean of $85.1 \pm 13.8 \mathrm{msec}$, while IVCT 2 was between 30 and $109 \mathrm{msec}$, with a mean of 57.3 $\pm 17.5 \mathrm{msec}$. The LVET was between 295 and 436 msec, with a mean of $349 \cdot 3 \pm 34.3 \mathrm{msec}$. The majority of patients were found to have a LVET more than $340 \mathrm{msec}$. The LVET/IVCT I ratio was between 2.9 and 6.5 , with a mean of 4.3 , and the LVET/IVCT 2 ratio was between 3.3 and 14.0 , with a mean of 6.7.

When the measurements of the above systolic intervals and ratios in patients with idiopathic hypertrophic subaortic stenosis were compared with the peak systolic intraventricular pressure gradient, no correlation could be established (Fig. 5).

\section{Discussion}

The measurement of systolic time intervals has been applied by many investigators to the evaluation of left ventricular function in nonvalvular heart disease (Margolis, 1964; Schoenfeld et al., 1967; Weissler et al., 1969). It was found that haemodynamic measurements of left ventricular performance correlate significantly with the externally measured systolic time intervals (Garrard, Weissler, and Dodge, 1970; Ahmed et al., 1970). In patients with valvular aortic stenosis and idiopathic hypertrophic subaortic stenosis, attention has been focused on the ejection time, carotid arterial pulse contour, and its different measurements, with little notice taken of the other components of systole.

The measurement of the Q-Mr interval in patients with valvular aortic stenosis by different investigators has yielded conflicting results (Warembourg and Dubar, 1967; Braunwald et al., 1963; Delahaye et al., 1968). We have selected our patients carefully to avoid errors in evaluating the length of the Q-MI interval; associated mitral stenosis, left bundle-branch block, left ventricular failure - or false timing of the aortic ejection sound as the onset of the first heart sound. We found that the Q-MI interval was moderately prolonged (mean $=66.3 \mathrm{msec}$ ). In patients with idiopathic hypertrophic subaortic stenosis an abnormally long Q-MI interval was found (mean $=78.4 \mathrm{msec}$ ); the majority of patients had an interval more than 70 msec (Fig. 6). It seems possible that left ventricular hypertrophy may be responsible for the delay of the intraventricular spread of the electric stimulus. Modification of the elastic properties of the myocardial fibres in left ventricular hypertrophy may lead to a delay in the transformation of the cardiac ovoid into a sphere, hence the preisometric phase of contraction ( $\mathrm{Q}-\mathrm{MI}$ ) will be prolonged (Warembourg and Dubar, 1967). However, there was no correlation between the peak systolic pressure gradient and the Q-MI interval in both groups of patients.

Difficulty in defining the initial high-frequency vibrations of the first heart sound in patients with 
valvular aortic stenosis made it impossible to measure the IVCT 2 in 7 patients out of 26. This difficulty certainly limits the application of this measurement. In both groups of patients with valvular aortic stenosis and idiopathic hypertrophic subaortic stenosis, the IVCT I and IVCT 2 were found to be shorter than in normal subjects. IVCT is a direct expression of the sum of factors comprising contractility, especially the rate of rise of left ventricular pressure, and it also reflects the end-diastolic stretch and end-diastolic volume (Katz and Feil, 1923; Reeves et al., 1960; Spodick and Kumar, 1968). The shortening of IVCT in patients with valvular aortic stenosis and idiopathic hypertrophic subaortic stenosis might be due to an accelerated rise of the intraventricular pressure in addition to a diminished end-diastolic pressure gradient between the aorta and the left ventricle. Patients with subaortic stenosis have a high peak arterial dp/dt, due to the absence of obstruction to ejection early in systole (Mason et al., I964), which may in part explain the short IVCT.

There is, however, the probability that the hypertrophic ventricular muscle also participates in the shortening of IVCT. Jezek (1963) found this shortening to be much more conspicuous in patients with valvular aortic stenosis and conspicuous left ventricular hypertrophy. We found a significant inverse relation between the peak systolic pressure gradient and IVCT in patients with valvular aortic stenosis, patients with the most severe obstruction having the shortest IVCT. In patients with idiopathic hypertrophic subaortic stenosis no relation exists between the IVCT and the intraventricular pressure gradient. The variability of contractility and outflow obstruction in these patients may explain this lack of correlation. It must be borne in mind that idiopathic hypertrophic subaortic stenosis is a primary myocardial disease, resulting only secondarily in obstruction to left ventricular ejection; indeed, significant obstruction has never been documented in many patients who were severely incapacitated (Morrow, Lambrew, and Braunwald, 1964).

Pathological lengthening of LVET in patients similar to ours has been previously reported by various investigators (Donoso et al., 1956; Duchosal et al., 1956; Benchimol, Legler, and Dimond, 1963; Robinson, 1963; Epstein and Coulshed, 1964; Braunwald et al., 1964; Moskowitz and Wechsler, 1965; Wigle, Auger, and Marquis, 1967; Polis at al., 1968; Coblence et al., 1968; Delahaye et al., 1968). Contrary to the findings of Delahaye and coworkers (I968) in young patients with aortic stenosis we were not able to obtain a linear correlation between the peak systolic pressure gradient and LVET.
Our findings agree with those of Epstein and Coulshed (1964). In patients with idiopathic hypertrophic subaortic stenosis our findings are similar to those of Braunwald and coworkers (1964) who found no relation between the peak systolic pressure gradient and the duration of the ejection period. Wigle and coworkers (1967), on the other hand, found a direct relation between the degree of prolongation of the ejection time, and the magnitude of the intraventricular pressure gradient. In our two groups of patients the LVET was more than $340 \mathrm{msec}$ in the majority of cases and this was independent of the level of the gradient. However, contrary to the findings of Polis and coworkers (1968), we did not find normal ejection time in patients with severe valvular aortic stenosis. We think the lack of a good correlation between the gradient and LVET is due to the many factors which affect the latter. Though the degree of aortic valve obstruction is an important factor in determining the duration of the left ventricular ejection time, the stroke volume makes a significant contribution.

Since a high pressure gradient in the aortic orifice is mostly associated with a shortening of IVCT and a prolongation of the ejection time, we thought that a better correlation may exist when the LVET/ IVCT ratio is compared with the pressure gradient. We found a significant linear correlation between these two variables, especially when the LVET/ IVCT I ratio was applied $(r=0.84, P<0.001)$. Patients having a LVET/IVCT I ratio of more than 5 usually have a severe degree of aortic valve stenosis with a peak systolic pressure gradient across the aortic orifice more than $90 \mathrm{mmHg}$. Generally patients with a gradient less than $60 \mathrm{mmHg}$ have a LVET/IVCT I ratio near the normal (the estimated normal mean LVET/IVCT I ratio according to the measurements of Kumar and Spodick, 1970, is 3.1). However, this relation applies only to patients in the compensated state, since the addition of left ventricular failure will produce lengthening of IVCT and shortening of LVET.

In patients with valvular aortic stenosis an assessment of the systolic pressure gradient and the severity of stenosis can be obtained from external measurement of the IVCT and LVET/IVCT ratio. In patients with idiopathic hypertrophic subaortic stenosis no single parameter was found to be of value in assessing the degree of intraventricular pressure gradient and the severity of obstruction.

\section{References}

Ahmed, S. S., Levinson, G. E., Schwartz, C. J., and Ettinger, P. O. (1970). Comparison of systolic time intervals (STI) with direct measures of myocardial contractility in man (abstract). Clinical Research, 18, 294. 
Bazett, H. C. (1920). An analysis of the time-relations of the electrocardiograms. Heart, 7, 353.

Benchimol, A., Legler, J. F., and Dimond, E. G. (1963). The carotid tracing and apexcardiogram in subaortic stenosis and idiopathic myocardial hypertrophy. American fournal of Cardiology, 11, 427.

Braunwald, E., Goldblatt, A., Aygen, M. M., Rokoff, S. D. and Morrow, A. G. (1963). Congenital aortic stenosis. (I) Clinical and hemodynamic findings in 100 patients. Circulation, $27,426$.

Braunwald, E., Lambrew, C. T., Rockoff, S. D., Ross, J., and Morrow, A. G. (1964). Idiopathic hypertrophic subaortic stenosis: I. A description of the disease based upon an analysis of 64 patients. Circulation, 30, Suppl. IV, 3.

Coblence, B., Bourdarias, J. P., Gerbaux, A., Baragan, J., Mehrez, R., Sozutek, Y., and Lenègre, J. (1968). Corrélations entre tracés mécaniques externes et données hémodynamiques dans la myocardiopathie obstructive. In Actualités Cardio-Vasculaires Médico-Chirurgicales, $4^{\circ}$ serie, pp. 153-173. Ed. by R. Froment, A. Goninjad, and P. Michaud. Masson, Paris.

Delahaye, J.-P., Didierlaurent, J. F., Badoux, G., Gonin, A., and Froment, R. (1968). Corrélations entre les données phonomécanographiques externes, le type anatomique et les critères hémodynamiques de sévérité dans les sténoses aortiques orificielles et juxta-orificielles. Archives des Maladies du Coeur et des Vaisseaux, 61, 805.

Donoso, E., Sapin, S. O., Kuhn, L. A., and Grishman, A. (1956). The use of indirect arterial pressure pulse tracings in the diagnosis of congenital heart disease. (II) Congenital subaortic and aortic stenosis. Pediatrics, 18, 205.

Duchosal, P. W., Ferrero, C., Leupin, A., and Urdaneta, E. (1956). Advance in the clinical evaluation of aortic stenosis by arterial pulse recordings of the neck. American Heart fournal, 51, 86r.

Epstein, E. J., and Coulshed, N. (1964). Assessment of aortic stenosis from the external carotid pulse wave. British Heart fournal, 26, 84 .

Garrard, C. L., Jr., Weissler, A. M., and Dodge, H. T. (1970). Relationship of alterations in systolic time intervals to ejection fraction in patients with cardiac disease. Circulation, 42, 455 .

Jezek, V. (1963). Clinical value of the polygraphic tracing in the study of the sequence of events during cardiac contraction. Cardiologia, 43, 298.

Katz, L. N., and Feil, H. S. (1923). Clinical observations on the dynamics of ventricular muscle: (I) Auricular fibrillation. Archives of Internal Medicine, 32, 672.

Katz, L. N., and Feil, H. S. (1926). Clinical observations on the dynamics of ventricular systole. (II) Aortic stenosis and aortic insufficiency. Heart 12, 171 .

Kumar, S., and Spodick, D. H. (1970) Study of the mechanical events of the left ventricle by atraumatic techniques: comparison of methods of measurement and their significance. American Heart fournal, 80, $40 \mathrm{r}$.

Margolis, C. (1964). Significance of ejection period/tension period as a factor in the assessment of cardiac function and as a possible diagnostic tool for the uncovering of silent coronary heart disease: study of I I I cases. Diseases of the Chest, 46, 706.

Mason, D. T., Braunwald, E., Ross, J., Jr., and Morrow, A. G. (I964). Diagnostic value of the first and second derivatives of the arterial pressure pulse in aortic valve disease and in hypertrophic subaortic stenosis. Circulation, 30, 90.

Morrow, A. G., Lambrew, C. T., and Braunwald, E. (1964). Idiopathic hypertrophic subaortic stenosis: II. Operative treatment and the results of pre- and postoperative hemodynamic evaluations. Circulation, 30, Suppl. IV, 120.

Moskowitz, R. L., and Wechsler, B. M. (1965). Left ventricular ejection time in aortic and mitral valve disease. American fournal of Cardiology, 15, 809.

Polis, O., Vancrombreucq, J. C., Lanoy, M., and Page, W. (1968). Etude du temps d'ejection ventriculaire gauche à partir du pouls carotidien chez les sujets normaux et dans les sténoses aortiques. Archives des Maladies du Coeur et des Vaisseaux, 6r, 1738.

Reeves, T. J., Hefner, L. L., Jones, W. B., Coghlan, C., Prieto, G., and Carroll, J. (1960). The hemodynamic determinants of the rate of change in pressure in the left ventricle during isometric contraction. American Heart fournal, 60, 745 .

Robinson, B. (1963). The carotid pulse: I. Diagnosis of aortic stenosis by external recordings. British Heart fournal, 25, 5 I.

Schoenfeld, C. D., Robinson, J. L., Weissler, A. M., and Warren, J. V. (1967). Left ventricular systolic time intervals in myocardial infarction (abstract). Clinical Research, I5, 411 .

Spodick, D. H., and Kumar, S. (I968). Isovolumetric contraction period of the left ventricle. Results in a normal series and comparison of methods of calculation by atraumatic techniques. American Heart fournal, 76, 498.

Warembourg, H., and Dubar, P. (1967). La Méthode des Tracés Synchrones: Le Chronocardiogramme. Expansion Scientific Francaise, Paris.

Weissler, A. M., Harris, W. S., and Schoenfeld, C. D. (1968). Systolic time intervals in heart failure in man. Circulation, 37, 149.

Weissler, A. M., Harris, W. S., and Schoenfeld, C. D. (1969). Bedside technics for the evaluation of ventricular function in man. American fournal of Cardiology, 23, 577.

Wigle, E. D. (1963). The arterial pressure pulse in muscular subaortic stenosis. British Heart fournal, 25, 97.

Wigle, E. D., Auger, P., and Marquis, Y. (1967). Muscular subaortic stenosis. The direct relation between the intraventricular pressure difference and the left ventricular ejection time. Circulation, 36, 36.

Requests for reprints to Dr. M. Mohsen Ibrahim, Research Division, Cleveland Clinic, 2020 East 93rd Street, Cleveland, Ohio 44106, U.S.A. 